\title{
Managing Tumor Lysis Syndrome in the Era of Novel Cancer Therapies
}

\author{
ALI MCBRIDE, ${ }^{1}$ PharmD, MS, BCPS, BCOP, STEVEN TRIFILIO,${ }^{2}$ RPh, NADINE BAXTER, ${ }^{3}$ MNSC, \\ APN-BC, AOCNP ${ }^{\circledR}$, TARA K. GREGORY, ${ }^{4}$ MD, and SCOTT C. HOWARD, ${ }^{5}$ MD, MS
}

From The University of Arizona Cancer Center, Tucson, Arizona; ${ }^{2}$ Northwestern Memorial Hospital, Chicago, Illinois, 'University of Arkansas for Medical Sciences, Myeloma Institute for Research and Therapy, Little Rock, Arkansas;" COolorado Blood Cancer Institute at Presbyterian St. Luke's Medical Center, Denver, Colorado; 5 University of Memphis, School of Health Studies, Memphis, Tennessee

Authors' disclosures of potential conflicts of interest are found at the end of this article.

Correspondence to: Ali McBride, PharmD, MS, BCPS, BCOP, The University of Arizona Cancer Center, 3838 N. Campbell Avenue, PO Box 245219, Tucson, AZ 85719. E-mail: Ali.McBride@uahealth.com https://doi.org/10.6004/jadpro.2017.8.7.4 (c) 2017 Harborside ${ }^{\text {TM }}$

\begin{abstract}
Tumor lysis syndrome (TLS) is a potentially life-threatening emergency that can develop rapidly after the release of intracellular contents from lysed malignant cells. The advent of novel and targeted therapies that have improved tumor-killing efficacy has the potential to increase the risk of TLS when used as part of front-line therapy. A recent review of TLS risk in patients with hematologic malignancies treated with newer targeted agents highlighted the need to revisit TLS risk stratification and to describe the practical challenges of TLS prevention, treatment, and monitoring. Although this era of rapid development of novel cancer therapies provides new hope for patients with hematologic malignancies, it is essential to be prepared for TLS because monitoring and prophylaxis can almost always prevent severe and life-threatening consequences. Heightened awareness of the development of TLS with novel and targeted agents, accompanied by aggressive hydration and rational, risk-appropriate management, are the keys to successful outcomes.
\end{abstract}

J Adv Pract Oncol 2017;8:705-720

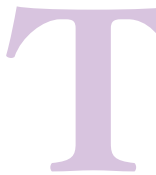

umor lysis syndrome (TLS) is a potentially lifethreatening emergency that can develop rapidly after the release of intracellular contents from lysed malignant cells (Cairo, Coiffier, Reiter, Younes, \& TLS Expert Panel, 2010; Howard, Jones, \& Pui, 2011; Wilson \& Berns, 2014). Characterized by hyperuricemia, hyperkalemia, hyperphosphatemia, and hypocalcemia, TLS results from the inability of homeostatic mechanisms to respond to the rapid release of intracellular contents such as nucleic acids (which are rapidly converted to uric acid), phosphate, and potassium into the blood (Howard et al., 2011; Wilson \& Berns, 2014). It can occur spontaneously, especially in patients with high-grade malignancies, but it most commonly occurs soon after initiation of chemotherapy. Tumor lysis syndrome can lead to renal failure, arrhythmia, seizures, or death. Patients with less severe complications can suffer significant morbidity and increased health-care costs (Cairo et al., 2010; Mughal, Ejaz, Foringer, \& Coiffier, 2010). Prompt management 
of TLS can reduce morbidity and mortality in patients being treated for hematologic malignancies, and identification of at-risk patients can often prevent TLS altogether.

Cancer treatments have evolved from traditional cytotoxic chemotherapies to more targeted molecular or biologic agents with markedly different mechanisms of action. These novel targeted cancer agents have not only enhanced antitumor efficacy but also have fewer side effects and, in some cases, increased convenience when available as oral formulations. For example, in 2001, the tyrosine kinase inhibitor (TKI) imatinib was approved for the treatment of patients with chronic-phase chronic myeloid leukemia (CML) on the basis of unprecedented single-agent response rates, even among patients with interferon-resistant disease (O'Brien et al., 2003). Since then, enhanced understanding of the molecular aberrations underlying malignancy has enabled development of multiple targeted agents, including marketed drugs and many others in active clinical development. Despite their advantages and, indeed, because of their enhanced anticancer activity, such therapies may increase TLS risk, including in patients with diseases not previously linked to TLS (e.g., chronic lymphocytic leukemia [CLL] and multiple myeloma). However, the extent to which these novel targeted agents influence the risk of TLS in a given tumor type is not well characterized.

In this article, we provide a practical guide on TLS in the context of new cancer therapies; review previously published strategies for identifying TLS risk; discuss key insights from a systematic literature review (Howard, Trifilio, Gregory, Baxter, \& McBride, 2015); revisit risk stratification in light of new therapies; and highlight practical challenges of TLS prevention, treatment, and monitoring, with insights applicable to community practice.

\section{CURRENT MODELS TO IDENTIFY PATIENTS AT RISK FOR TLS}

Current schemas for identifying TLS risk factors focus primarily on tumor and patient characteristics (Cairo et al., 2010; Howard et al., 2011; Mughal et al., 2010). In 2010, an expert panel published recommendations for evaluating TLS risk (low, intermediate, or high) in adult and pediatric patients with cancer. Risk was classified by the type of ma- lignancy, with solid tumors generally considered low risk, except for bulky chemotherapy-sensitive entities such as neuroblastoma, germ cell tumors, and small cell lung cancer, which were categorized as intermediate risk (Cairo et al., 2010). Hematologic malignancies were also first characterized by type, with multiple myeloma and the chronic leukemias grouped under the low-risk category, except for CLL treated with targeted and/or biologic therapies, which increased the risk for TLS to intermediate (CLL treated with alkylating agents was low risk). Acute leukemias were further stratified as acute myeloid leukemia (AML), acute lymphoblastic leukemia (ALL), or Burkitt lymphoma/ leukemia. All Burkitt leukemias were considered high risk, as were AML or ALL with white blood cell (WBC) counts $\geq 100 \times 10^{9} / \mathrm{L}$ and ALL with a WBC count $<100 \times 10^{9} / \mathrm{L}$ but lactate dehydrogenase $\geq 2 \times$ the upper limit of normal. Classification of TLS risk with various lymphomas followed an increasingly complex algorithm.

For all malignancies, risk was adjusted at the final step based on renal function, with shifts to higher-risk categories for patients with low- or intermediate-risk and renal dysfunction and/or renal involvement or for those with normal renal function but elevated uric acid, phosphate, or potassium levels (Cairo et al., 2010). With only one exception (increased TLS risk in patients with CLL who receive biologic or targeted treatment), the type of therapy was not used to determine TLS risk.

A second publication considered TLS risk based on four major categories of risk factors: cancer mass, cell-lysis potential of the tumor, patient characteristics at presentation, and supportive care (Howard et al., 2011). The potential for cell lysis depends not only on the chemosensitivity of the cancer cells but also on the intensity (or efficacy) of the initial anticancer therapy used, with higher intensity (efficacy) conferring a higher risk. Given the potential of highly effective novel and targeted therapies to increase the risk of TLS when used as part of initial anticancer therapy, we recommend that the particular type of therapy receive increased focus when assessing risk. Table 1 provides a practical guide for assessing tumor bulk in hematologic malignancies and can be utilized in an algorithm for TLS risk stratification based on cancer, cancer treatment, and patient factors (Figure 1). 


\section{RISK FOR TLS WITH NEW AND EMERGING TREATMENTS}

To explore whether new and emerging agents are associated with TLS, we conducted a systematic review of TLS associated with selected molecular and biologic agents. Articles published between January 2010 and October 2014 for phase I to III clinical trials in hematologic malignancies with novel monoclonal antibodies, TKIs, protease inhibitors, chimeric antigen receptor (CAR) T cells, and the proapoptotic agent lenalidomide (Revlimid) were retrieved from the literature and analyzed (Table 2; Howard et al., 2015).

Overall, the incidence of TLS varied greatly across agents and cancer types. With the use of two agents, idelalisib (Zydelig) and ofatumumab (Arzerra), no TLS was reported. Agents for which the TLS incidence was $<5 \%$ included brentuximab vedotin (Adcetris; Pro et al., 2012), carfilzomib (Kyprolis; Berenson et al., 2014; Jagannath et al., 2012; Siegel et al., 2013; Siegel et al., 2012; Sonneveld et al., 2012), dasatinib (Sprycel; Rousselot et al., 2010), lenalidomide (Badoux et al., 2011; Badoux et al., 2013; Chen et al., 2011; Fehniger et al., 2011; Goy et al., 2013;
Morschhauser et al., 2013; Wendtner et al., 2012; Witzig et al., 2009), and oprozomib (Ghobrial et al., 2013).

Two phase I trials of venetoclax (ABT-199; Venclexta) reported a TLS incidences $>5 \%$ (Seymour et al., 2013, 2014) in relapsed or refractory CLL (8.3\% and $8.9 \%$, respectively), with one fatality per trial. These fatalities led to interruption of the clinical development of ABT-199 and resulted in a stepwise dosing schema specifically to mitigate TLS risk. The incidence of TLS was $10 \%$ in a 10-patient phase II trial of CAR T cells (Kochenderfer et al., 2013) and in a 40-patient phase II trial of obinutuzumab in relapsed or refractory aggressive non-Hodgkin lymphoma (NHL; Morschhauser et al., 2011). A phase II trial of dinaciclib in 20 patients with advanced ALL or AML reported a $15 \%$ TLS incidence, including 1 fatality from acute renal failure despite aggressive prophylaxis and hemodialysis (in a patient with AML and pretreatment laboratory TLS; Gojo et al., 2013). The highest incidences of TLS, $42 \%$ and $53 \%$, occurred in phase II studies of alvocidib in a sequential regimen with cytarabine and mitoxantrone in poor-risk AML (Karp et al., 2007, 2010).

\section{Table 1. Tumor Bulk Assessment for Hematologic Malignancies}

\begin{tabular}{|c|c|c|c|}
\hline & Low (0) & Intermediate (1) & High (2) \\
\hline Tumor masses & $\begin{array}{l}\text { No tumor or metastatic } \\
\text { lesions }>2 \mathrm{~cm}^{a}\end{array}$ & $\begin{array}{l}\text { Multiple lesions but no more } \\
\text { than two bulky ones }(6-10 \\
\mathrm{cm})\end{array}$ & $\begin{array}{l}\text { Many bulky lesions (diameter } \\
6-10 \mathrm{~cm} \text { ) or one or more } \\
\text { very bulky lesions }(>10 \mathrm{~cm} \text { ) }\end{array}$ \\
\hline Bone marrow & Uninvolved & $\begin{array}{l}\text { Partially infiltrated by } \\
\text { cancer cells ( } 5 \%-49 \% \text { tumor } \\
\text { cellularity) }\end{array}$ & $\begin{array}{l}\text { Bone marrow replaced by } \\
\text { cancer cells }(50 \%-100 \% \\
\text { tumor cellularity) }\end{array}$ \\
\hline Spleen & Normal & $\begin{array}{l}\text { Moderate splenomegaly } \\
\text { (palpable but }<5 \mathrm{~cm} \text { below } \\
\text { the costal margin) }\end{array}$ & $\begin{array}{l}\text { Massive splenomegaly } \\
\text { (palpable } \geq 5 \mathrm{~cm} \text { below the } \\
\text { costal margin) }\end{array}$ \\
\hline Liver & Normal & $\begin{array}{l}\text { Moderate hepatomegaly } \\
\text { (palpable but }<5 \mathrm{~cm} \text { below } \\
\text { the costal margin) }\end{array}$ & $\begin{array}{l}\text { Massive hepatomegaly } \\
\text { (palpable } \geq 5 \mathrm{~cm} \text { below the } \\
\text { costal margin) }\end{array}$ \\
\hline Lymph nodes & $\begin{array}{l}\text { Normal lymph nodes or } \\
\text { minimal lymphadenopathy }\end{array}$ & $\begin{array}{l}\text { Extensive nonbulky } \\
\text { lymphadenopathy with no } \\
\text { more than two bulky lymph } \\
\text { nodes }(6-10 \mathrm{~cm})\end{array}$ & $\begin{array}{l}\text { Many bulky lymph nodes } \\
\text { (diameter } 6-10 \mathrm{~cm} \text { ) or one } \\
\text { or more very bulky lymph } \\
\text { nodes }(>10 \mathrm{~cm} \text { ) }\end{array}$ \\
\hline Kidneys & Normal & $\begin{array}{l}\text { Mild to moderate } \\
\text { nephromegaly or small lesions } \\
(<2 \mathrm{~cm}) \text { visible by imaging }\end{array}$ & $\begin{array}{l}\text { Significant nephromegaly or } \\
\text { large lesions }(\geq 2 \mathrm{~cm}) \text { visible } \\
\text { by imaging }\end{array}$ \\
\hline \multicolumn{4}{|c|}{$\begin{array}{l}\text { Note. Used with kind permission of Scott Howard. } \\
\text { a Unless otherwise specified, all measurements refer to the greatest diameter of the lesion. Measurements may be made } \\
\text { by physical examination or imaging. The total cancer mass is reflected by the "Bulk Score" comprised of the sum of all } \\
\text { components as follows: score of } 0=\text { small; score of } 1-2=\text { medium; score of } 3-4=\text { large; score of } 5-12=\text { very large. }\end{array}$} \\
\hline
\end{tabular}



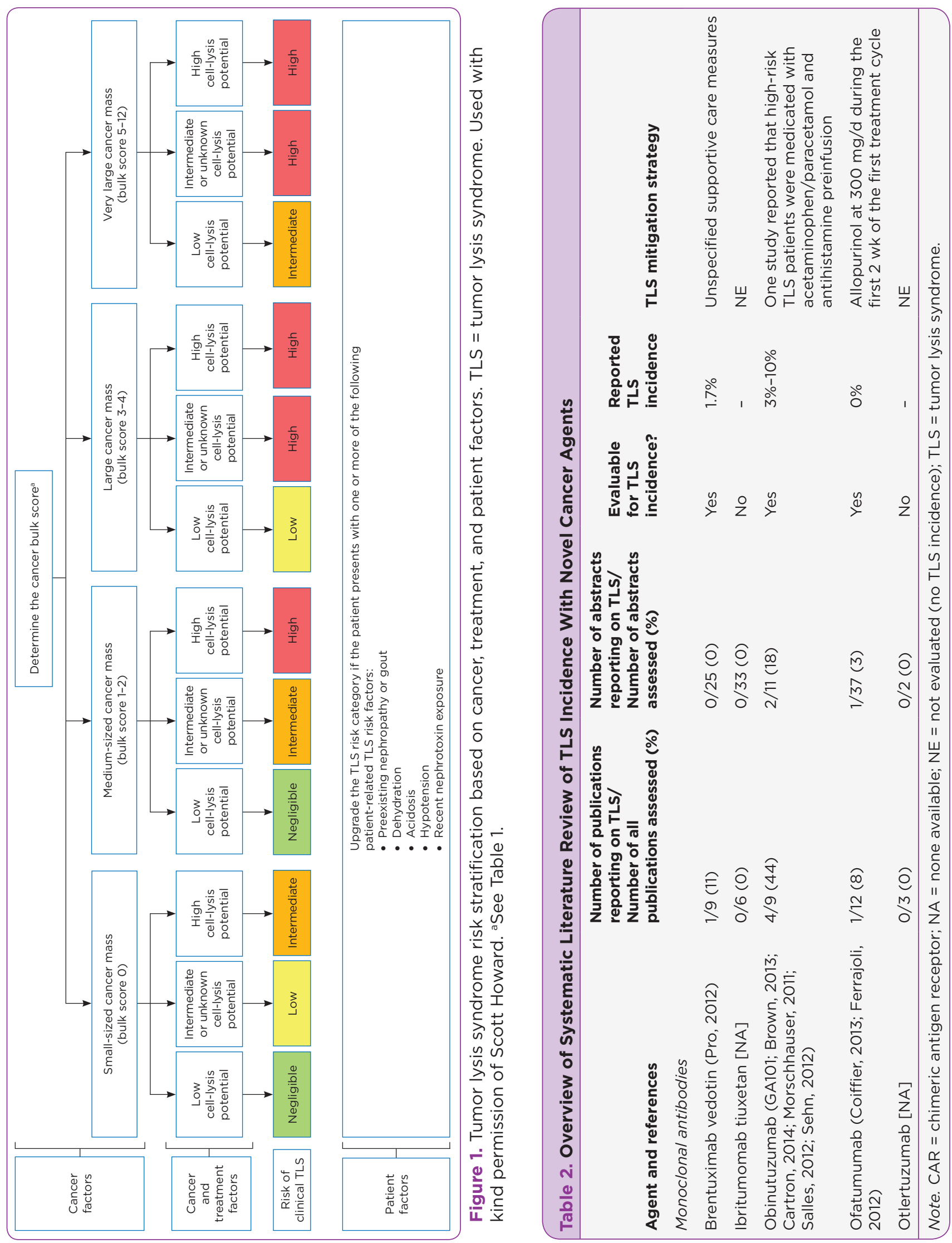


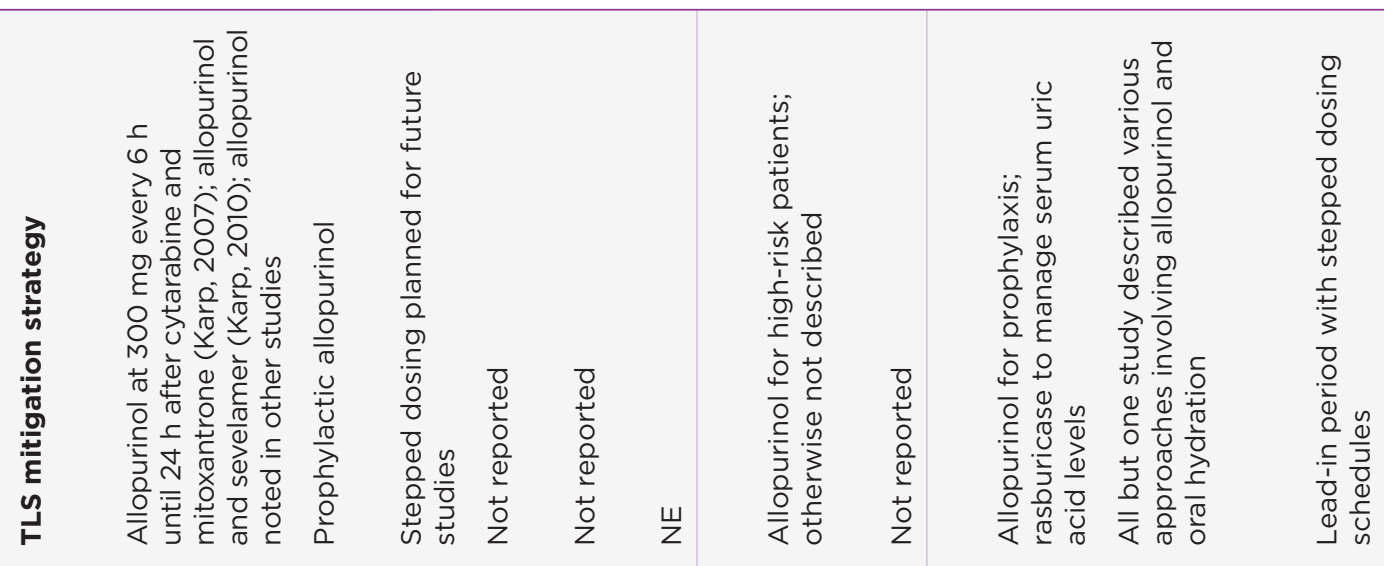

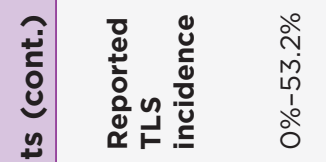
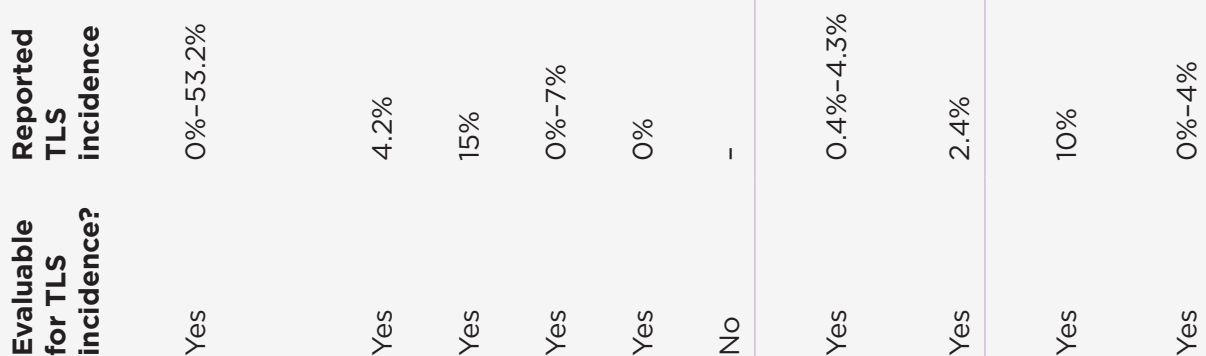

$\stackrel{๊}{\nu}$

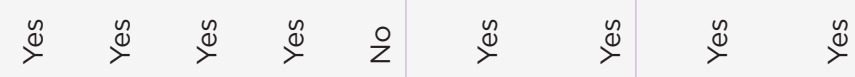
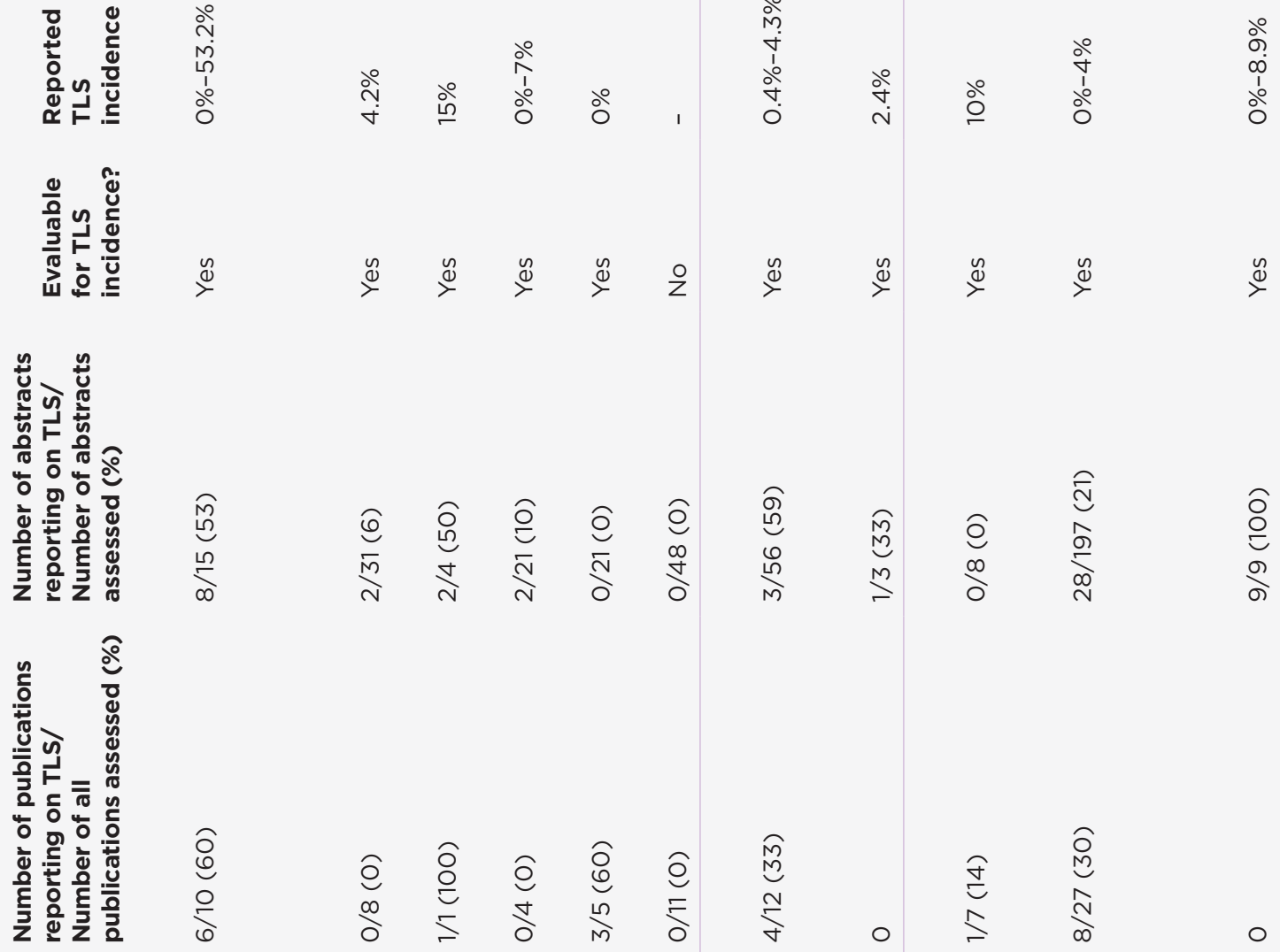

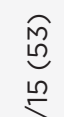

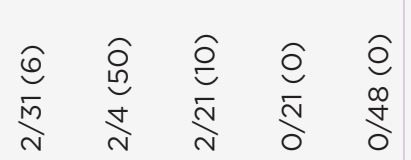

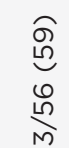

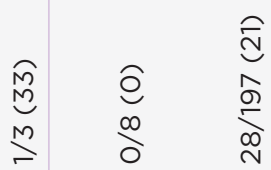

$\frac{0}{0}$
$\frac{0}{a}$<smiles>O=C1CCCCC1</smiles>

官

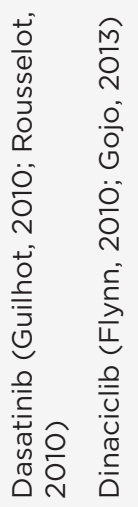

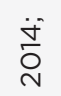
ह่ำ

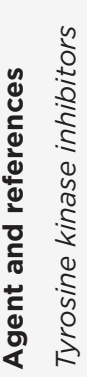

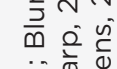

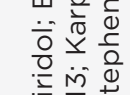
言完荝 융

$\stackrel{\text { กั }}{\stackrel{2}{2}}$

ণับ

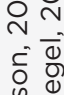

$\frac{1}{2}$
$\frac{2}{2}$
$\frac{0}{0}$
$\frac{0}{0}$
$\frac{0}{0}$
$\frac{5}{0}$

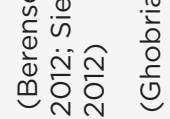
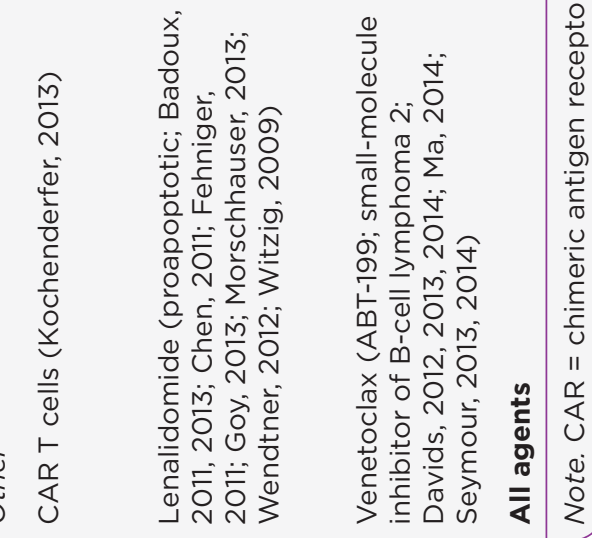


\section{CLINICAL CHALLENGES}

\section{TLS Management and Control of Uric Acid}

Prophylactic management for patients at risk for TLS consists of vigorous hydration, therapies that decrease the production of uric acid (e.g., allopurinol) or enzymatically remove it (e.g., rasburicase [Elitek]; Howard et al., 2011; Wilson \& Berns, 2014) as well as the avoidance of exogenous potassium and phosphorus. Because the primary goal of prophylactic management is prevention of clinical TLS, close monitoring is required to detect metabolic abnormalities before they cause symptoms.

The current treatment options for controlling uric acid in the setting of TLS are allopurinol and rasburicase. Allopurinol reduces the production of uric acid but has no effect on current uric acid levels. Rasburicase can immediately reduce existing uric acid levels and is also effective when the tumor burden is anticipated to be high, thus alleviating the risk of tumor lysis. Recently, febuxostat (Uloric), a non-purine selective inhibitor, was approved by the US Food and Drug Administration (FDA) for chronic management of hyperuricemia in patients with gout (Takeda
Pharmaceuticals U.S.A., Inc., 2013), is currently being studied in the TLS setting.

Allopurinol and febuxostat inhibit xanthine oxidase, the enzyme that converts hypoxanthine to xanthine and xanthine to uric acid (Figure 2; $\mathrm{Hu}$ \& Tomlinson, 2008; Pession, Melchionda, \& Castellini, 2008), and thus prevent the formation of new uric acid from purines released by cancer cell lysis, reducing both serum and urinary levels of uric acid. In a phase III clinical trial, allopurinol (300 mg/day orally) administered to adults on days 1 to 5 resulted in a response rate (defined as uric acid levels $\leq 7.5 \mathrm{mg} / \mathrm{dL}$ for all measurements from days $3-7$ ) of $66 \%$ (95\% confidence interval $[\mathrm{CI}]=56 \%-76 \%$; Cortes et al., 2010). When used to prevent uric acid nephropathy from anticancer therapy, it is recommended to administer as a high volume of fluid with allopurinol 600 to $800 \mathrm{mg} /$ day orally (Prometheus Laboratories Inc., 2009). The allopurinol dose must be adjusted, however, in patients with acute kidney injury because it is renally cleared. A dose-dependent decrease in serum and urinary uric acid levels can be expected within 2 to 3 days.

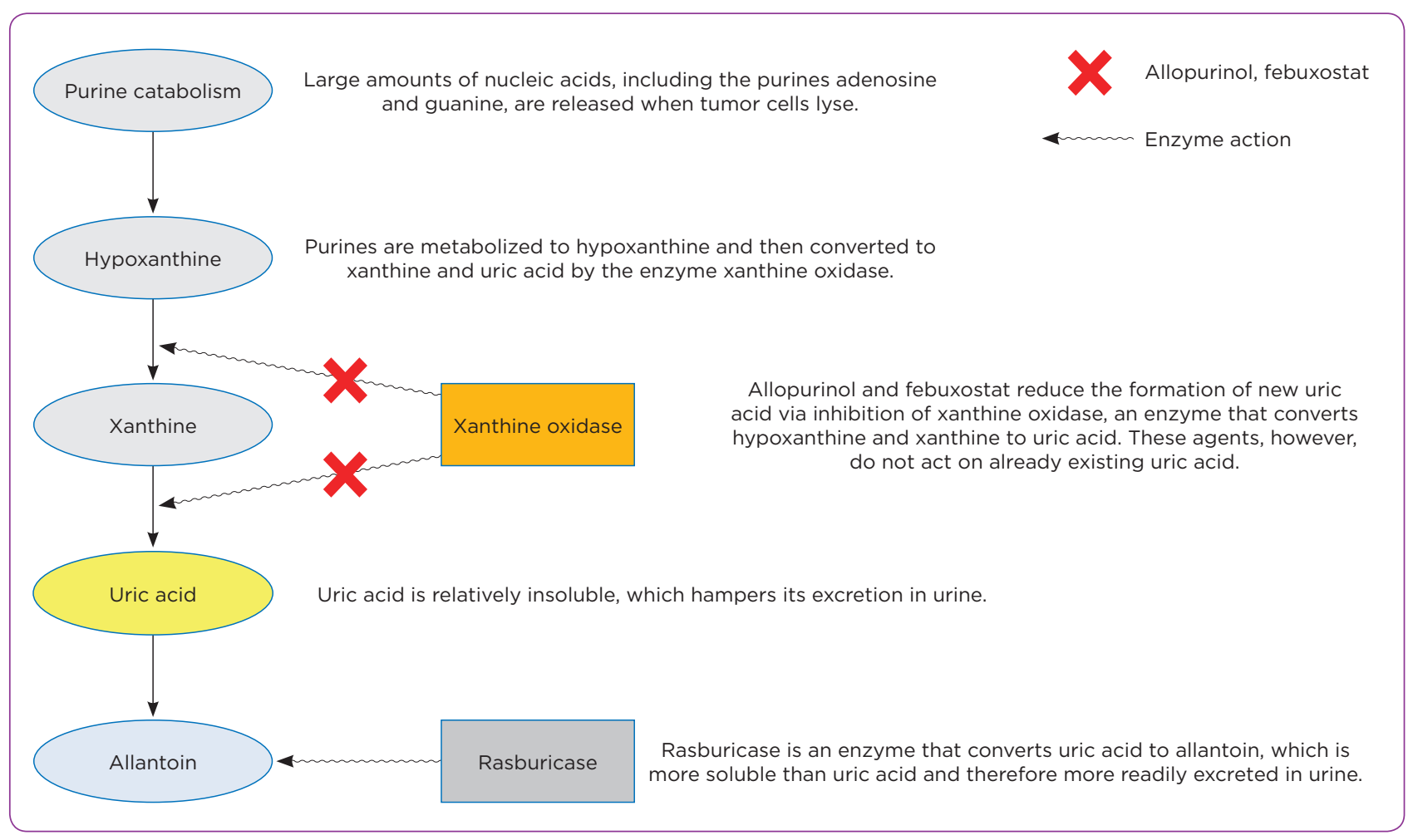

Figure 2. Mechanism of action for allopurinol, febuxostat, and rasburicase. Information from Sanofiaventis (2011); Hu \& Tomlinson (2008); Pession et al. (2008). 
Skin rashes or other signs or symptoms of an allergic reaction should prompt immediate discontinuation, with further use contraindicated after any severe reactions (allergic or otherwise). Bendamustine carries a warning against the concomitant use of allopurinol because of severe skin reactions (such as Stevens-Johnson syndrome; Teva Pharmaceutical Industries Ltd., 2016). Recently, febuxostat was shown to reduce elevated uric acid levels associated with TLS, with efficacy comparable (Maie et al., 2014) or superior to allopurinol (Spina et al., 2015).

Rasburicase is a recombinant urate oxidase that reduces uric acid blood levels by converting uric acid into allantoin (Figure 2), which is more soluble than uric acid (Bose \& Qubaiah, 2011). Rasburicase is indicated for the initial management of plasma uric acid levels in patients (pediatric and adult) with leukemia, lymphoma, and solid tumors in whom chemotherapy would be expected to result in TLS and plasma uric acid elevation (Howard et al., 2011; Sanofi-aventis, 2011). The FDA-approved regimen for rasburicase is $0.2 \mathrm{mg} /$ $\mathrm{kg} /$ day as a 30-minute intravenous infusion for up to 5 days (Sanofi-aventis, 2011).

Eight studies supported regulatory approval, including studies demonstrating significantly greater uric acid lowering vs. allopurinol in pediatric acute leukemia or NHL (Goldman et al., 2001) and higher response rates vs. allopurinol in adult leukemia, lymphoma, or other hematologic malignancy ( $87 \%$ vs. $66 \%$; Cortes et al., 2010). After considering accumulating data from compassionate-use trials in which rasburicase demonstrated efficacy at lower doses and over a shorter duration of therapy, an expert panel concluded that dosing may be $0.1,0.15$, and $0.2 \mathrm{mg} / \mathrm{kg}$ for low-, intermediate-, and high-risk disease, respectively, for 1 to 7 days (Coiffier, Altman, Pui, Younes, \& Cairo, 2008). Note, however, that although not evidence based, fixed-dose regimens are used in some institutions.

One retrospective series used fixed low doses of rasburicase of $1.5,3,4.5$, or $6 \mathrm{mg}$ to treat hyperuricemia secondary to TLS, with a response rate of $80 \%$ (reduction of uric acid to $<8 \mathrm{mg} / \mathrm{dL}$ in 31 of 39 adult patients with a baseline above this threshold) after initial dosing (Herrington \& Dinh, 2014). In the largest retrospective study $(\mathrm{N}=373)$ conducted in patients with hematologic malignancy or solid tumors who were receiving rasburicase for TLS prevention (McBride et al., 2013), no difference was observed for the achievement of normalized plasma uric acid level ( $<7.5 \mathrm{mg} / \mathrm{dL}) 24$ hours after administration of a single fixed $(3,6$, or $7.5 \mathrm{mg})$ or weight-based ( $\geq 0.1 \mathrm{mg} / \mathrm{kg}$ ) rasburicase dose. Other studies of fixed-dose rasburicase have demonstrated uric acid-lowering efficacy (Herrington \& Dinh, 2014). Unfortunately, no adequately powered study of low-dose vs. fixed-dose vs. standard-dose rasburicase has been conducted in patients at intermediate risk of TLS, so optimal use of rasburicase in this group remains controversial.

Rasburicase is contraindicated in patients with a history of anaphylaxis or severe hypersensitivity reactions to rasburicase. Repeated exposure to rasburicase can lead to hypersensitivity reactions in patients who receive an initial course of rasburicase and later require another dose (or series of doses) to manage TLS at the time of relapse (Allen et al., 2015). Rasburicase is also contraindicated in patients with glucose6-phosphate dehydrogenase (G6PD) deficiency, an $\mathrm{X}$-linked condition associated with a risk for hemolytic anemia and potential methemoglobinemia consequent to the hydrogen peroxide production that occurs with rasburicase (Relling et al., 2014; Sanofi-aventis, 2011). In clinical studies, hemolysis or methemoglobinemia occurred in $<1 \%$ of patients who received rasburicase (Sanofi-aventis, 2011).

Patients with G6PD deficiency should receive allopurinol instead of rasburicase (Cairo et al., 2010). Men of African, Middle Eastern, or Mediterranean origin have an incidence of G6PD deficiency as high as $20 \%$ (Relling et al., 2014), although it should be noted that patients can carry a G6PD deficiency irrespective of ancestry. Optimally, testing would occur at the time of intake into the oncology practice before rasburicase administration (Relling et al., 2014). Established deficiency per genotyping is sufficient for contraindication, but the limitations of genotyping typically warrant G6PD enzyme testing.

If uric acid levels are high and testing will be delayed, patients with no personal/family history suggestive of G6PD deficiency may receive a small dose of rasburicase $(1.5 \mathrm{mg})$, with testing 4 hours later for laboratory evidence of hemolysis (i.e., changes in hemoglobin, haptoglobin, and biliru- 
bin; Elinoff, Salit, \& Ackerman, 2011). If uric acid levels remain high and no hemolysis is evident, additional rasburicase can be administered safely. For those with hematologic cancers, G6PD activity should be measured at presentation because many patients receive red blood cell transfusions soon after diagnosis, and transfusion can mask G6PD deficiency (Bucklin \& Groth, 2013).

\section{Use of Uric Acid-Lowering Medications Based on TLS Risk}

Allopurinol is typically used in patients at low risk of clinical TLS, and rasburicase is used in those at high risk (or who present with TLS). For intermediate-risk patients, a single dose of rasburicase may be used to eliminate existing uric acid, followed by allopurinol to prevent formation of new uric acid. Alternatively, initial allopurinol use (to decrease new uric acid formation) may be combined with hyperhydration to remove existing uric acid. Regardless of the initial chosen strategy, serial uric acid measurements should guide continued therapy. If uric acid increases despite allopurinol, rasburicase can be used as subsequent rescue; however, this strategy has the disadvantage of allowing accumulation of xanthine, which is not removed by subsequent rasburicase administration.

For individualized selection of rasburicase dose, considerations include the patient's baseline uric acid level, rate of increase from the baseline uric acid level, anticipated increase due to tumor load, effectiveness of therapy to lyse the tumor, and the uric acid goal. It is important to note that repeat dosing may be necessary for patients in whom initial dosing does not achieve the desired reduction in uric acid levels after 4 hours (Coiffier et al., 2008), with the potential to eliminate the need for hemodialysis in these patients who may have highly chemosensitive or rapidly dividing tumors. In our experience, a single dose of rasburicase may also be used in patients at intermediate risk of clinical TLS, with reassessment to determine the need for a second dose (Howard et al., 2011). Regardless of the initial TLS risk category or initial therapy, patients who develop acute kidney injury and have persistent hyperuricemia while taking allopurinol should receive a dose of rasburicase to remove existing uric acid and mitigate the risk for ongoing renal damage.
Obese patients are of particular concern for uric acid management. In a single-center retrospective analysis of 151 patients, body mass index did not correlate with failure of fixed-dose rasburicase in adults, but the study did not have sufficient statistical power to compare outcomes in obese vs. nonobese patients, particularly in the relevant (controversial) subset at intermediate risk for TLS (Clemmons, Ensley, Hoge, \& Clark, 2014). The study's findings were similar to those published in a previous report (McBride et al., 2013).

Although earlier consensus guidelines prohibited the concomitant use of allopurinol with rasburicase to avoid xanthine accumulation and lack of substrate for rasburicase (Tosi et al., 2008), limited evidence suggests this combination may be beneficial, although not synergistic, and in general rasburicase is so effective at reducing uric acid that once a decision is made to administer it, allopurinol would not be necessary as an adjunct (Cortes et al., 2010). With either allopurinol or rasburicase, avoiding concomitant drugs that increase uric acid (Table 3 ) is recommended.

The National Comprehensive Cancer Network (NCCN) recommendations include both allopurinol and rasburicase as options, specifying that rasburicase is appropriate for NHL patients with certain risk factors (i.e., high-risk features, highbulk disease, inadequate hydration, acute renal failure; NCCN, 2014a) and should be considered as initial treatment in AML associated with rapidly increasing blasts, high uric acid, or impaired renal function (NCCN, 2014b). The NCCN NHL Guidelines note that allopurinol should begin 2 to 3 days before chemotherapy and continue for 10 to 14 days, whereas one dose of rasburicase is frequently adequate (NCCN, 2014a). Intravenous rather than oral allopurinol can be used; however, 2 to 3 days are still required to reduce uric acid levels, because the mechanism of action is not the removal of existing uric acid but a reduction in the formation of new uric acid.

\section{Monitoring in Emergent and Community Settings}

Published guidelines suggest that laboratory and clinical TLS parameters (levels of uric acid, phosphate, potassium, calcium, and lactate dehydrogenase in addition to measurements of fluid 


\begin{tabular}{|c|c|}
\hline Drug type & Examples \\
\hline Alcoholic beverages & Any \\
\hline Antiuricosuric drugs & Pyrazinamide, ethambutol, diclofenac, probenecid \\
\hline Methylxanthine drugs & Theophylline \\
\hline Thiazide and thiazide-like diuretics & $\begin{array}{l}\text { Bendroflumethiazide, hydroflumethiazide, cyclopenthiazide, chlorthalidone, } \\
\text { metolazone, hydrochlorothiazide }\end{array}$ \\
\hline Loop diuretics & Ethacrynic acid, furosemide, acetazolamide, bumetanide \\
\hline Hormones & Epinephrine, norepinephrine, angiotensin, testosterone \\
\hline Salicylates & Sodium salicylate, aspirin at low doses \\
\hline Antirejection therapy & Cyclosporine \\
\hline Sugar substitutes & Xylitol \\
\hline Xanthine oxidase inhibitor & Benzbromarone \\
\hline Other & Nicotinic acid fructose, lactate \\
\hline
\end{tabular}

input and urine output) should be monitored 4 to 6 hours after initial chemotherapy administration in pediatric patients at high risk (Coiffier et al., 2008; Howard et al., 2011). These guidelines recommend that adult patients at intermediate risk be monitored for at least 24 hours after the completion of chemotherapy (Coiffier et al., 2008). Our recommendation is to tailor the monitoring interval according to the three categories of TLS risk (Table 4), with even more intense monitoring in the event of treatment-emergent clinical TLS (Howard et al., 2011).

The optimal frequency of electrolyte and uric acid monitoring depends on the clinical TLS risk. In patients who receive rasburicase, monitoring should occur every 4 to 6 hours to ensure that serum uric acid is within a safe range. We give additional rasburicase doses (at a reduced dose) as needed whenever uric acid starts to increase again after a previous dose; and we continue monitoring until clinical laboratory parameters (including a complete metabolic panel, complete blood cell count, magnesium, phosphorus, as well as uric acid) are within normal limits or until chemotherapy induction is completed. However, if low doses of rasburicase $(<0.15-0.2 \mathrm{mg} /$ $\mathrm{kg}$ examined in prospective clinical trials) are used initially, uric acid may require more frequent monitoring to detect rising levels.

It is important to note that rasburicase results in enzymatic degradation of uric acid ex vivo when blood samples are drawn and remain at room temperature. To avoid artificially low measured uric acid levels in patients who have received rasburicase, blood samples should be collected in prechilled heparin-containing tubes and immediately transferred to an ice water bath, with centrifugation utilizing a precooled centrifuge. At that time, plans need to be in place to assay the samples within 4 hours after collection.

\section{Management Practices With New Agents for Hematologic Cancers}

Our survey of TLS in association with new agents yielded little specific information on the mitigation strategies employed. For alvocidib, mitigation utilized oral allopurinol at $300 \mathrm{mg}$ every 6 hours until 24 hours after cytarabine and mitoxantrone in the initial trial (Karp et al., 2007), with both allopurinol and sevelamer in the subsequent trial (Karp et al., 2010). Mitigation of TLS was employed across all of the clinical trials of alvocidib that reported TLS (either specifying allopurinol or stated more generally and additionally delaying alvocidib initiation in one combination trial). Routine TLS prophylaxis occurred in clinical trials of lenalidomide due to a high rate seen in an early clinical trial in CLL (Moutouh-de Parseval, Weiss, DeLap, Knight, \& Zeldis, 2007). Including fatalities, TLS occurred during the early clinical development of ABT- 


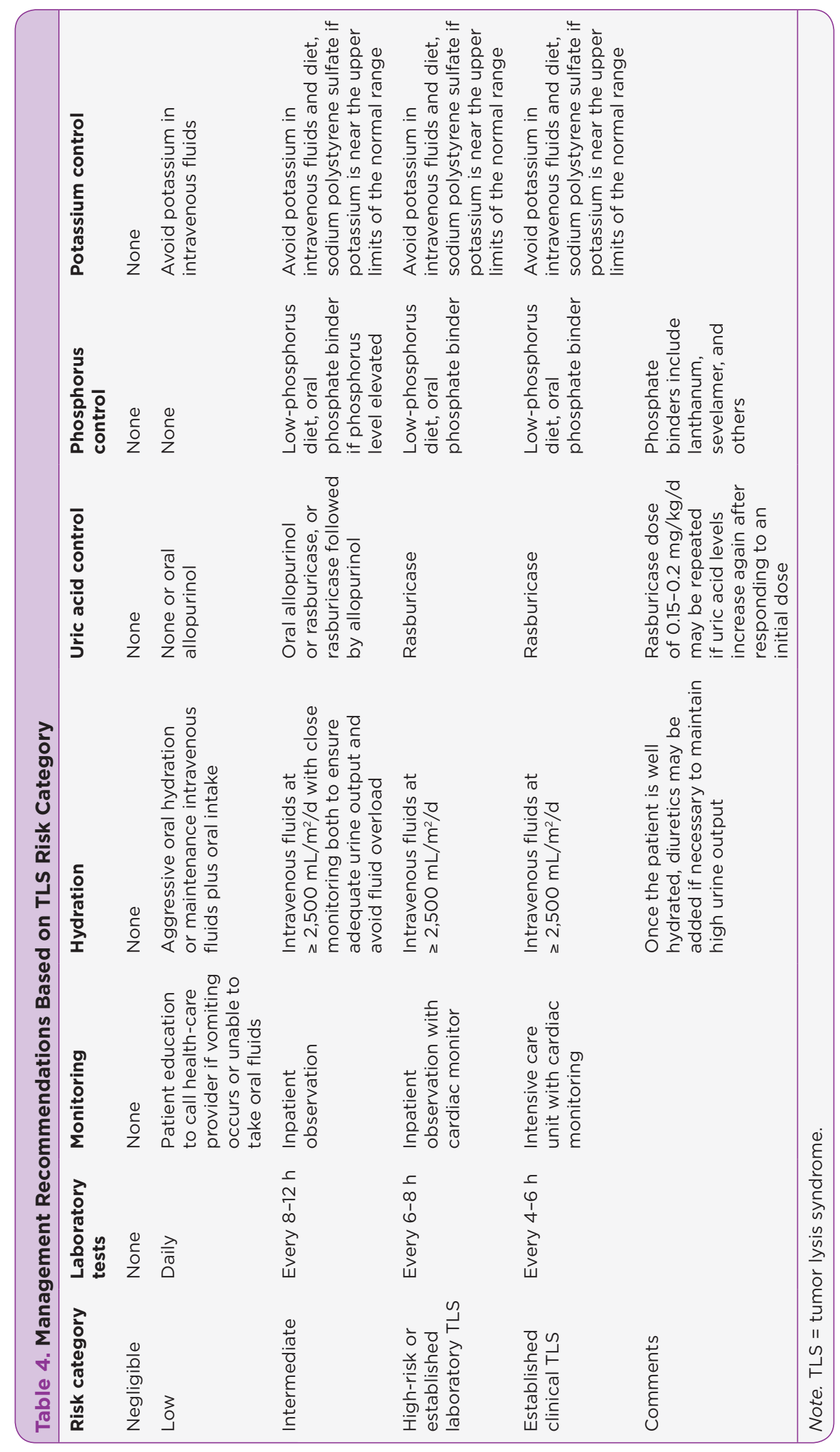


199, prompting the protocols to adopt a stepwise dosing schema specifically intended to mitigate TLS risk. Rasburicase was rarely mentioned, except in a phase I trial of alvocidib in combination with cyclophosphamide and rituximab in high-risk CLL in which it was given with the first two courses as part of a comprehensive regimen that also included allopurinol at $300 \mathrm{mg}$, hydration, urine alkalinization, and a phosphate binder (Stephens et al., 2013). Overall, the TLS mitigation strategy was not mentioned or was stated in general terms for a number of trials (Table 2), questioning whether the protocols had captured mitigation in their supportive care guidelines.

\section{KNOWLEDGE GAPS}

Knowledge gaps are as follows:

- Information on the specific TLS prophylaxis strategies that are used in clinical trials of novel cancer agents for hematologic malignancies is rarely reported (Table 2).

- The limited available clinical trial evidence suggests that TLS is an important complication of novel and targeted therapies, which varies across agents and tumor types.

- Dinaciclib-treated patients with advanced leukemias, venetoclax-treated patients with CLL, and especially alvocidib-treated patients with AML appear to be at highest risk of TLS, although there is at least some risk with most surveyed agents (Table 1; Howard et al., 2015).

- As these molecules become more widely used, it is essential to learn more about which strategies should be initiated, with consideration of the type of therapy being a key factor in the overall risk assessment.

The overarching goal of TLS prevention is avoidance, yet breakthrough cases occur despite aggressive prophylaxis. For example, in the randomized trial of rasburicase alone, rasburicase plus allopurinol, or allopurinol alone in patients with hematologic malignancies at high risk for hyperuricemia and TLS, the incidences of clinical TLS (at least two laboratory abnormalities coupled with signs or symptoms of organ damage, including acute kidney injury, seizure, or arrhythmia) was $3 \%, 3 \%$, and $4 \%$, respectively, with corresponding laboratory TLS rates of $21 \%, 27 \%$, and
$41 \%$ and acute renal failure rates of $2 \%, 5 \%$, and $2 \%$ (Cortes et al., 2010). All patients received an initial dose of study medication 4 to 24 hours before initiating chemotherapy. It was recommended, but not required, that normal or half-normal saline be initiated at a rate of 4 to $5 \mathrm{~L} /$ day, starting 24 to 48 hours before chemotherapy.

The extent to which different practices of hydration, left to investigator discretion, may have influenced the TLS rates is unknown. Elderly patients and those with impaired cardiac and renal function are often unable to tolerate vigorous hydration and may therefore be candidates for early rasburicase treatment. The safety of reduced doses of rasburicase requires a prospective study in patients at intermediate TLS risk. In addition, concomitant rasburicase for upfront prophylaxis require further evaluation based on current reported differences in dosing between these investigational agents, as seen with alvocidib and other agents.

Moving forward, community oncologists, nurses, advanced practitioners and others who care for patients with hematologic malignancies would benefit from a clear-cut pathway for determining the optimal approaches for prevention and management of TLS as they pertain to a given cancer agent. In the hope that our experience in treating patients with TLS may be useful to others, we offer a collection of clinical pearls (Table 5) and a suggested approach to patient management (Table 6).

\section{CONCLUSIONS}

This era of rapid development of novel cancer therapies provides new hope for patients who suffer from hematologic malignancies. However, the promise of these agents can only be realized by avoiding death or complications from TLS, which is due, paradoxically, to the very nature of their higher efficacy. Heightened awareness of the development of TLS with novel and targeted agents, accompanied by aggressive hydration and rational therapy, is key to successful treatment outcomes.

\section{Acknowledgments}

Editorial and medical writing support was provided by Laurie Orloski, PharmD, and Mariana Ovnic, PhD, of Complete Publication Solutions, LLC. This support was provided by Sanofi-aventis. 


\section{Table 5. Best Practices for Successful Prevention and Treatment of TLS: Clinical Pearls}

- Forewarned is forearmed: All oncology patients are at risk of TLS.

»Patients should have an assessment of tumor bulk and estimated TLS risk to guide management, which includes monitoring and prophylaxis.

- The consequences of TLS are dire, so immediate recognition and a quick remedy are essential.

- Emesis and dehydration can increase the risk of clinical TLS, especially in patients managed in the ambulatory setting (Krishnan, D’Silva, \& Al-Janadi, 2008).

- Hemodialysis is needed in patients whose TLS is not promptly recognized and treated. In a study of patients with high-grade non-Hodgkin lymphoma, the incidence of TLS was $6 \% ; 45 \%$ of these patients experienced acute renal failure, and 37\% died (Annemans et al., 2003).

- Increase in creatinine of $0.3 \mathrm{mg} / \mathrm{dL}$ constitutes acute kidney injury and means the patient has developed laboratory TLS.

- An increasing creatinine level is a red flag. Rasburicase should be administered promptly.

- Initial target uric acid levels should be as low as possible to minimize the risk of uric acid crystallization in the kidneys and of non-crystal-induced injury. After 2 to 3 days of therapy, uric acid levels should be maintained in the normal range.

- G6PD-deficiency genotype should be determined before administration of rasburicase when possible (Relling et al., 2014).

- In a large observational study, a median 4-mg/dL uric acid reduction occurred $24 \mathrm{~h}$ after a single 3-mg rasburicase dose (Trifilio et al., 2011). Patients with pretreatment elevated uric acid levels (> $12 \mathrm{mg} / \mathrm{dL}$ ) are more likely to fail to respond to a single dose of rasburicase and should therefore be initiated on higher empiric doses.

- Close follow-up is critical for patients who received reduced-dose rasburicase; repeat uric acid measurement should be performed $4 \mathrm{~h}$ after the dose and repeated at intervals determined by TLS risk.

- Careful handling of samples from patients treated with rasburicase is necessary to obtain accurate uric acid levels; samples should be kept on ice and delivered to the laboratory for immediate testing. Allopurinol, however, does not break down uric acid in serum samples.

Note. glucose-6-phosphate dehydrogenase = G6PD; TLS = tumor lysis syndrome.

\section{Disclosure}

Dr. McBride has served on speakers bureaus for AbbVie and Incyte. The other authors have no potential conflicts of interest to disclose.

\section{References}

Allen, K. C., Champlain, A. H., Cotliar, J. A., Belknap, S. M., West, D. P., Mehta, J., \& Trifilio, S. M. (2015). Risk of anaphylaxis with repeated courses of rasburicase: A Research on Adverse Drug Events and Reports (RADAR) project. Drug Safety, 38(2), 183-187. https://doi. org/10.1007/s40264-014-0255-7

Annemans, L., Moeremans, K., Lamotte, M., Garcia Conde, J., van den Berg, H., Myint, H.,...Uyttebroeck, A. (2003). Incidence, medical resource utilisation and costs of hyperuricemia and tumour lysis syndrome in patients with acute leukaemia and non-Hodgkin's lymphoma in four European countries. Leukemia and Lymphoma, 44(1), 77-83. http://dx.doi.org/10.1080/1042819021000054661

Badoux, X. C., Keating, M. J., Wen, S., Lee, B. N., Sivina, M., Reuben, J.,...Ferrajoli, A. (2011). Lenalidomide as initial therapy of elderly patients with chronic lymphocytic leukemia. Blood, 118(13), 3489-3498. https://doi. org/10.1182/blood-2011-03-339077

Badoux, X. C., Keating, M. J., Wen, S., Wierda, W. G., O’Brien, S. M., Faderl, S.,...Ferrajoli, A. (2013). Phase II study of lenalidomide and rituximab as salvage therapy for patients with relapsed or refractory chronic lymphocytic leuke- mia. Journal of Clinical Oncology, 31(5), 584-591. https:// doi.org/10.1200/JCO.2012.42.8623

Berenson, J. R., Hilger, J. D., Yellin, O., Dichmann, R., PatelDonnelly, D., Boccia, R. V.,...Vescio, R. A. (2014). Replacement of bortezomib with carfilzomib for multiple myeloma patients progressing from bortezomib combination therapy. Leukemia, 28(7), 1529-1536. https://doi. org/10.1038/leu.2014.27

Blum, W., Phelps, M. A., Klisovic, R. B., Rozewski, D. M., Ni, W., Albanese, K. A.,...Grever, M. R. (2010). Phase I clinical and pharmacokinetic study of a novel schedule of flavopiridol in relapsed or refractory acute leukemias. Haematologica, 95(7), 1098-1105. https://doi.org/10.3324/ haematol.2009.017103

Bose, P., \& Qubaiah, O. (2011). A review of tumour lysis syndrome with targeted therapies and the role of rasburicase. Journal of Clinical Pharmacy and Therapeutics, 36(3), 299-329. https://doi.org/10.1111/j.1365-2710.2011.01260.x

Brown, J. R., Byrd, J. C., Coutre, S. E., Benson, D. M., Flinn, I. W., Wagner-Johnston, N. D.,...Furman, R. R. (2014). Idelalisib, an inhibitor of phosphatidylinositol 3-kinase pllodelta, for relapsed/refractory chronic lymphocytic leukemia. Blood, 123(22), 3390-3397. https://doi. org/10.1182/blood-2013-11-535047

Brown, J. R., O’Brien, S., Kingsley, C. D., Eradat, H., Pagel, J. M., Lymp, J.,...Kipps, T. J. (2013). Safety and efficacy of obinutuzumab (GA101) with fludarabine/cyclophosphamide (G-FC) or bendamustine (G-B) in the initial therapy of 


\section{Table 6. Suggested Approach to Tumor Lysis Management}

Upon initial visit of a new oncology patient, a G6PD level should be considered in appropriate patients to determine whether rasburicase is needed to reduce uric acid levels.

Initiate TLS labs every $6 \mathrm{~h}$, to begin $12 \mathrm{~h}$ after chemotherapy begins and continue for $48 \mathrm{~h}$ after infusion.

- TLS labs are considered to be potassium, BUN, creatinine, phosphate, LDH, and uric acid.

- Notify physician on call if:

»Urine output is $<2 \mathrm{~mL} / \mathrm{kg} / \mathrm{h}$ for any 4 -h period

" Potassium > ULN or $25 \%$ increase from previous value, and query the need for an electrocardiogram and cardiac monitoring, additional IV hydration of normal saline, and sodium polystyrene sulfonate

» Phosphate > ULN or $25 \%$ increase from previous value, and query the need for additional IV hydration and phosphate binders

»BUN increases by $10 \mathrm{mg} / \mathrm{dL}$ from baseline, and query the need for additional hydration, nephrology consultation, and use of rasburicase

»Creatinine increases by $0.3 \mathrm{mg} / \mathrm{dL}$ from previous value, and query the need for additional hydration and a nephrology consultation

"Uric acid > ULN or $25 \%$ increase from previous value, and query the need for additional hydration and the use of rasburicase

» LDH elevation > ULN and increasing, and query the need for additional hydration

Please note: When notifying the physician of changes in lab values, always have current vital signs, intake and output, and the patient's clinical status available. Query the need to pause chemotherapy to slow the rate of tumor lysis.

Continuous cardiac monitoring

Strict input and output monitoring

Low-phosphorus, low-potassium diet

No less than 64 oz oral noncaffeine intake in $24 \mathrm{~h}$

IV fluids

- Saline lock - insert

"With saline flush $0.9 \%$

- Sodium chloride $0.9 \%$ at $1,000 \mathrm{~mL}$ IV every $6 \mathrm{~h}$ (rate: $150 \mathrm{~mL} / \mathrm{h}$ )

- Sodium chloride $0.9 \%$ at 1,000 mL IV every $5 \mathrm{~h}$ (rate: $200 \mathrm{~mL} / \mathrm{h}$ )

Please note: Central venous catheter access is preferred.

Medications

- Allopurinol

" Load with $300 \mathrm{mg}$ po bid $\times 48 \mathrm{~h}$, then $200 \mathrm{mg}$ po bid

Please note: Allopurinol will not break down the current uric acid level.

- Rasburicase

» $1.5 \mathrm{mg}$ IV in $50 \mathrm{cc}$ of sodium chloride $0.9 \%$ at $100 \mathrm{cc}$ per $\mathrm{h}$

» 3-7.5 mg IV in $100 \mathrm{cc}$ of sodium chloride $0.9 \%$ at $100 \mathrm{cc}$ per $\mathrm{h}$

Please note: Do not give to patients with G6PD deficiency.

- Phosphate-lowering agents

- Calcium acetate

» $667 \mathrm{mg}$ po tid with meals if phosphate is 3.5 to $5.5 \mathrm{mg} / \mathrm{dL}$

» $1,337 \mathrm{mg}$ po tid with meals if phosphate is $>5.5 \mathrm{mg} / \mathrm{dL}$

Please note: IV calcium replacement should be considered.

Note. bid = twice a day; BUN = blood urea nitrogen; G6PD = glucose-6-phosphate dehydrogenase; IV = intravenously; $\mathrm{LDH}=$ lactate dehydrogenase; $\mathrm{po}=$ by mouth; tid = three times a day; TLS = tumor lysis syndrome; ULN = upper level of the normal range.

aDosing of rasburicase is institution-specific and may vary from 3 to $7.5 \mathrm{mg}$ based on the current tumor lysis protocol.

patients with Chronic Lymphocytic Leukemia (CLL): Results from the phase $1 \mathrm{~b}$ galton trial (GAO4779g) [Abstract 523]. Blood (ASH Annual Meeting Abstracts), 122(21).

Bucklin, M. H., \& Groth, C. M. (2013). Mortality following rasburicase-induced methemoglobinemia. Annals of Pharmacotherapy, 47(10), 1353-1358. https://doi. org/10.1177/1060028013501996
Cairo, M. S., Coiffier, B., Reiter, A., Younes, A., \& TLS Expert Panel. (2010). Recommendations for the evaluation of risk and prophylaxis of tumour lysis syndrome (TLS) in adults and children with malignant diseases: An expert TLS panel consensus. British Journal of Haematology, 149(4), 578-586. https://doi.org/10.1111/j.1365-2141.2010.08143.x

Cartron, G., de Guibert, S., Dilhuydy, M. S., Morschhauser, 
F., Leblond, V., Dupuis, J.,...Hallek, M. (2014). Obinutuzumab (GA101) in relapsed/refractory chronic lymphocytic leukemia: Final data from the phase 1/2 GAUGUIN study. Blood, 124(14), 2196-2202. https://doi.org/10.1182/ blood-2014-07-586610

Chen, C. I., Bergsagel, P. L., Paul, H., Xu, W., Lau, A., Dave, N.,...Trudel, S. (2011). Single-agent lenalidomide in the treatment of previously untreated chronic lymphocytic leukemia. Journal of Clinical Oncology, 29(9), 1175-1181. https://doi.org/10.1200/JCO.2010.29.8133

Clemmons, A. B., Ensley, E., Hoge, S., \& Clark, S. (2014). Fixed-dose rasburicase in overweight and obese patients versus normal-weight patients. Annals of Pharmacotherapy, 48(9), 1152-1158. https://doi. org/10.1177/1060028014539144

Coiffier, B., Altman, A., Pui, C. H., Younes, A., \& Cairo, M. S. (2008). Guidelines for the management of pediatric and adult tumor lysis syndrome: An evidence-based review. Journal of Clinical Oncology, 26(16), 2767-2778. https:// doi.org/10.1200/JCO.2007.15.0177

Coiffier, B., Radford, J., Bosly, A., Martinelli, G., Verhoef, G., Barca, G.,...study, i. (2013). A multicentre, phase II trial of ofatumumab monotherapy in relapsed/progressive diffuse large B-cell lymphoma. British Journal of Haematology, 163(3), 334-342. https://doi.org/10.1111/bjh.12537

Cortes, J., Moore, J. O., Maziarz, R. T., Wetzler, M., Craig, M., Matous, J.,...Seiter, K. (2010). Control of plasma uric acid in adults at risk for tumor lysis syndrome: Efficacy and safety of rasburicase alone and rasburicase followed by allopurinol compared with allopurinol alone-Results of a multicenter phase III study. Journal of Clinical Oncology, 28(27), 4207-4213. https://doi.org/10.1200/ JCO.2009.26.8896

Davids, M. S., Roberts, A. W., Anderson, M. A., Pagel, J. M., Kahl, B. S., Gerecitano, J. F.,...Seymour, J. F. (2012). The BCL2-specific BH3-mimetic ABT-199 (GDC-0199) is active and well-tolerated in patients with relapsed non-Hodgkin lymphoma: interim results of a phase I study [Abstract 304]. Blood (ASH Annual Meeting Abstracts), 120(21).

Davids, M. S., Seymour, J. F., Gerecitano, J. F., Kahl, B. S., Pagel, J. M., Wierda, W. G.,...Roberts, A. W. (2013). Updated results of a phase I first-in-human study of the BCL-2 inhibitor ABT-199 (GDC-0199) in patients with relapsed/ refractory non-Hodgkin lymphoma (NHL) [Abstract 8520]. Journal of Clinical Oncology (ASCO Annual Meeting Abstracts), 31(15 suppl). https://doi.org/10.1200/ jco.2013.31.15_suppl.8520

Davids, M. S., Seymour, J. F., Gerecitano, J. F., Kahl, B. S., Pagel, J. M., Wierda, W. G.,...Roberts, A. W. (2014). Phase I study of ABT-199 (GDC-0199) in patients with relapsed/ refractory $(\mathrm{R} / \mathrm{R})$ non-Hodgkin lymphoma (NHL): Responses observed in diffuse large B-cell (DLBCL) and follicular lymphoma (FL) at higher cohort doses [Abstract 8522]. Journal of Clinical Oncology (ASCO Annual Meeting Abstracts), 32(15 suppl).

Elinoff, J. M., Salit, R. B., \& Ackerman, H. C. (2011). The tumor lysis syndrome. New England Journal of Medicine, 365(6), 571-572; author reply 573-574. https://doi.org/10.1056/ NEJMc1106641

Farooqui, M., Aue, G., Valdez, J., Saba, N., Herman, S. E. M., Lipsky, A.,...Wiestner, A. (2012). Rapid decrease in overall tumor burden on ibrutinib (PCI-32765) in CLL despite transient increase in ALC indicates a significant degree of treatment induced cell death [Abstract 2899]. Blood (ASH Annual Meeting Abstracts), 120(21).

Fehniger, T. A., Larson, S., Trinkaus, K., Siegel, M. J., Cashen, A. F., Blum, K. A.,...Bartlett, N. L. (2011). A phase 2 multicenter study of lenalidomide in relapsed or refractory classical Hodgkin lymphoma. Blood, 118(19), 5119-5125. https://doi.org/10.1182/blood-2011-07-362475

Ferrajoli, A., Falchi, L., O’Brien, S., Wierda, W., Faderl, S., Smith, S. C.,...Keating, M. J. (2012). Combination of ofatumumab and lenalidomide in patients with relapsed chronic lymphocytic leukemia (CLL): Results of a phase II trial [Abstract 720]. Blood (ASH Annual Meeting Abstracts), $120(21)$.

Flinn, I. W., Kahl, B. S., Leonard, J. P., Furman, R. R., Brown, J. R., Byrd, J. C.,...Spurgeon, S. E. (2014). Idelalisib, a selective inhibitor of phosphatidylinositol 3-kinase-delta, as therapy for previously treated indolent non-Hodgkin lymphoma. Blood, 123(22), 3406-3413. https://doi. org/10.1182/blood-2013-11-538546

Flynn, J. M., Jones, J. A., Andritsos, L., Blum, K. A., Johnson, A. J., Hessler, J.,...Byrd, J. C. (2010). Update on the phase I study of the cyclin dependent kinase inhibitor dinaciclib $\mathrm{SCH}$ 727965) in patients with relapsed or refractory chronic lymphocytic leukemia (CLL): Confirmation of clinical activity and feasibility of long-term administration [Abstract 1396]. Blood (ASH Annual Meeting Abstracts), 116(21).

Ghobrial, I. M., Kaufman, J. L., Siegel, D. S., Vij, R., Badros, A., Neuman, L.,...Savona, M. (2013). Clinical profile of single-agent modified-release oprozomib tablets in patients (PTS) with hematologic malignancies: Updated results from a multicenter, open-label, dose escalation phase 1B/2 study [Abstract 3184]. Blood (ASH Annual Meeting Abstracts), 122(21).

Gojo, I., Sadowska, M., Walker, A., Feldman, E. J., Iyer, S. P., Baer, M. R.,...Bannerji, R. (2013). Clinical and laboratory studies of the novel cyclin-dependent kinase inhibitor dinaciclib (SCH 727965) in acute leukemias. Cancer Chemotherapy and Pharmacology, 72(4), 897-908. https:// doi.org/10.1007/s00280-013-2249-z

Goldman, S. C., Holcenberg, J. S., Finklestein, J. Z., Hutchinson, R., Kreissman, S., Johnson, F. L.,...Cairo, M. S. (2001). A randomized comparison between rasburicase and allopurinol in children with lymphoma or leukemia at high risk for tumor lysis. Blood, 97(10), 2998-3003. https:// doi.org/10.1182/blood.V97.10.2998

Goy, A., Sinha, R., Williams, M. E., Kalayoglu Besisik, S., Drach, J., Ramchandren, R.,...Witzig, T. E. (2013). Singleagent lenalidomide in patients with mantle-cell lymphoma who relapsed or progressed after or were refractory to bortezomib: Phase II MCL-001 (EMERGE) study. Journal of Clinical Oncology, 31(29), 3688-3695. https:// doi.org/10.1200/JCO.2013.49.2835

Guilhot, F., Kantarjian, H., Shah, N. P., Hochhaus, A., Brigid Bradley-Garelik, M., Dejardin, D., \& Cortes, J. E. (2010). Dasatinib (versus imatinib) in patients (pts) with newly diagnosed chronic myeloid leukemia in chronic phase (CML-CP): Analysis of safety and efficacy by use of baseline medications in the DASISION trial [Abstract 2295]. Blood (ASH Annual Meeting Abstracts), 116(21).

Herrington, J. D., \& Dinh, B. C. (2014). Fixed, low-dose rasburicase for the treatment or prevention of hyperuricemia in adult oncology patients. Journal of Oncology Pharmacy Practice, 21(2), 111-117. https://doi. 
org/10.1177/1078155214520821

Holkova, B., Perkins, E. B., Ramakrishnan, V., Tombes, M. B., Shrader, E., Talreja, N.,...Grant, S. (2011). Phase I trial of bortezomib (PS-341; NSC 681239) and alvocidib (flavopiridol; NSC 649890) in patients with recurrent or refractory B-cell neoplasms. Clinical Cancer Research, 17(10), 3388-3397. https://doi.org/10.1158/1078-0432. CCR-10-2876

Holkova, B., Supko, J. G., Ames, M. M., Reid, J. M., Shapiro, G. I., Perkins, E. B.,...Grant, S. (2013). A phase I trial of vorinostat and alvocidib in patients with relapsed, refractory, or poor prognosis acute leukemia, or refractory anemia with excess blasts-2. Clinical Cancer Research, 19(7), 1873-1883. https://doi.org/10.1158/1078-0432.CCR-12-2926

Howard, S. C., Jones, D. P., \& Pui, C. H. (2011). The tumor lysis syndrome. New England Journal of Medicine, 364(19), 1844-1854. https://doi.org/10.1056/NEJMra0904569

Howard, S. C., Trifilio, S., Gregory, T. K., Baxter, N., \& McBride, A. (2015). Tumor lysis syndrome in the era of novel and targeted agents in patients with hematologic malignancies: A systematic review. Annals of Hematology, 95(4), 563-573. https://doi.org/10.1007/s00277-015-2585-7

$\mathrm{Hu}, \mathrm{M} .$, \& Tomlinson, B. (2008). Febuxostat in the management of hyperuricemia and chronic gout: A review. Therapeutics and Clinical Risk Management, 4(6), 1209-1220.

Jagannath, S., Vij, R., Stewart, A. K., Trudel, S., Jakubowiak, A. J., Reiman, T.,...Siegel, D. S. (2012). An open-label singlearm pilot phase II study (PX-171-003-A0) of low-dose, single-agent carfilzomib in patients with relapsed and refractory multiple myeloma. Clinical Lymphoma, Myeloma \& Leukemia, 12(5), 310-318. https://doi.org/10.1016/j. clml.2012.08.003

Kahl, B. S., Spurgeon, S. E., Furman, R. R., Flinn, I. W., Coutre, S. E., Brown, J. R.,...Wagner-Johnston, N. D. (2014). A phase 1 study of the PI3Kdelta inhibitor idelalisib in patients with relapsed/refractory mantle cell lymphoma (MCL). Blood, 123(22), 3398-3405. https://doi. org/10.1182/blood-2013-11-537555

Karp, J. E., Blackford, A., Smith, B. D., Alino, K., Seung, A. H., Bolanos-Meade, J.,...Wright, J. J. (2010). Clinical activity of sequential flavopiridol, cytosine arabinoside, and mitoxantrone for adults with newly diagnosed, poor-risk acute myelogenous leukemia. Leukemia Research, 34(7), 877-882. https://doi.org/10.1016/j.leukres.2009.11.007

Karp, J. E., Smith, B. D., Levis, M. J., Gore, S. D., Greer, J., Hattenburg, C.,...Colevas, A. D. (2007). Sequential flavopiridol, cytosine arabinoside, and mitoxantrone: A phase II trial in adults with poor-risk acute myelogenous leukemia. Clinical Cancer Research, 13(15 Pt 1), 4467-4473. https://doi.org/10.1158/1078-0432.CCR-07-0381

Kochenderfer, J. N., Dudley, M. E., Carpenter, R. O., Kassim, S. H., Rose, J. J., Telford, W.,...Gress, R. E. (2013). Donor-derived anti-CD19 chimeric-antigen-receptor-expressing $\mathrm{T}$ cells cause regression of malignancy persisting after allogeneic hematopoietic stem cell transplantation [Abstract 151]. Blood (ASH Annual Meeting Abstracts), 122(21).

Krishnan, G., D'Silva, K., \& Al-Janadi, A. (2008). Cetuximabrelated tumor lysis syndrome in metastatic colon carcinoma. Journal of Clinical Oncology, 26(14), 2406-2408. https://doi.org/10.1200/JCO.2007.14.7603

Lin, T. S., Blum, K. A., Fischer, D. B., Mitchell, S. M., Ruppert, A. S., Porcu, P.,...Byrd, J. C. (2010). Flavopiridol, fludarabine, and rituximab in mantle cell lymphoma and indolent B-cell lymphoproliferative disorders. Journal of Clinical Oncology, 28(3), 418-423. https://doi. org/10.1200/JCO.2009.24.1570

Ma, S., Seymour, J. F., Lanasa, M. C., Kipps, T. J., Barrientos, J. C., Davids, M. S.,...Roberts, A. W. (2014). ABT-199 (GDC0199) combined with rituximab in patients with relapsed/ refractory chronic lymphocytic leukemia: Interim results of a phase $1 \mathrm{~b}$ study [Abstract 7013]. Journal of Clinical Oncology (ASCO Annual Meeting Abstracts), 32(15 suppl).

Maie, K., Yokoyama, Y., Kurita, N., Minohara, H., Yanagimoto, S., Hasegawa, Y.,...Chiba, S. (2014). Hypouricemic effect and safety of febuxostat used for prevention of tumor lysis syndrome. Springerplus, 3, 501. https://dx.doi. org/10.1186\%2F2193-1801-3-501

McBride, A., Lathon, S. C., Boehmer, L., Augustin, K. M., Butler, S. K., \& Westervelt, P. (2013). Comparative evaluation of single fixed dosing and weight-based dosing of rasburicase for tumor lysis syndrome. Pharmacotherapy, 33(3), 295-303. https://doi.org/10.1002/phar.1198

Moriwaki, Y. (2014). Effects on uric acid metabolism of the drugs except the antihyperuricemics. Journal of Bioequivalence and Bioavailability, 6(1), 10-17. https://doi. org/10.4172/jbb.1000173

Morschhauser, F., Cartron, G., Thieblemont, C., Solal-Celigny, P., Haioun, C., Bouabdallah, R.,...Salles, G. A. (2011). Encouraging activity of obinutuzumab (GA101) monotherapy in relapsed/refractory aggressive non-Hodgkin's lymphoma: Results from a phase II study (BO20999) [Abstract 3655]. Blood (ASH Annual Meeting Abstracts), $118(21)$.

Morschhauser, F., Fitoussi, O., Haioun, C., Thieblemont, C., Quach, H., Delarue, R.,...Coiffier, B. (2013). A phase 2, multicentre, single-arm, open-label study to evaluate the safety and efficacy of single-agent lenalidomide (Revlimid) in subjects with relapsed or refractory peripheral T-cell non-Hodgkin lymphoma: The EXPECT trial. European Journal of Cancer, 49(13), 2869-2876. https://doi. org/10.1016/j.ejca.2013.04.029

Moutouh-de Parseval, L. A., Weiss, L., DeLap, R. J., Knight, R. D., \& Zeldis, J. B. (2007). Tumor lysis syndrome/tumor flare reaction in lenalidomide-treated chronic lymphocytic leukemia [Abstract 5047]. Journal of Clinical Oncology (ASCO Annual Meeting Abstracts), 25(31). https:// doi.org/10.1200/JCO.2007.14.2141

Mughal, T. I., Ejaz, A. A., Foringer, J. R., \& Coiffier, B. (2010). An integrated clinical approach for the identification, prevention, and treatment of tumor lysis syndrome. Cancer Treatment Reviews, 36(2), 164-176. https://doi. org/10.1016/j.ctrv.2009.11.001

National Comprehensive Cancer Network. (2014b). NCCN Clinical Practice Guidelines in Oncology: Acute myeloid leukemia. v2.2014. Retrieved from http://www.nccn.org/ professionals/physician_gls/pdf/aml.pdf

National Comprehensive Cancer Network. (2014a). NCCN Clinical Practice Guidelines in Oncology: Non-Hodgkin's lymphomas. v5.2014. Retrieved from http://www.nccn. org/professionals/physician_gls/pdf/nhl.pdf

O’Brien, S. G., Guilhot, F., Larson, R. A., Gathmann, I., Baccarani, M., Cervantes, F.,...Investigators, I. (2003). Imatinib compared with interferon and low-dose cytarabine for newly diagnosed chronic-phase chronic myeloid leukemia. New England Journal of Medicine, 348(11), 9941004. https://doi.org/10.1056/NEJMoa022457 
O’Brien, S. M., Barrientos, J. C., Flinn, I. W., Barr, P. M., Burger, J. A., Navarro, T.,...Brown, J. R. (2012). Combination of the Bruton's tyrosine kinase inhibitor PCI-32765 with bendamustine/rituximab in patients with relapsed/refractory chronic lymphocytic leukemia: Interim results of a phase Ib/II study [Abstract 6515]. Journal of Clinical Oncology (ASCO Annual Meeting Abstracts), 30(15 suppl).

Pession, A., Melchionda, F., \& Castellini, C. (2008). Pitfalls, prevention, and treatment of hyperuricemia during tumor lysis syndrome in the era of rasburicase (recombinant urate oxidase). Biologics: Targets and Therapy, 2(1), 129-141. https://doi.org/10.2147/BTT.S1522

Pro, B., Advani, R., Brice, P., Bartlett, N. L., Rosenblatt, J. D., Illidge, T.,...Shustov, A. (2012). Brentuximab vedotin (SGN-35) in patients with relapsed or refractory systemic anaplastic large-cell lymphoma: Results of a phase II study. Journal of Clinical Oncology, 30(18), 2190-2196. https://doi.org/10.1200/JCO.2011.38.0402

Prometheus Laboratories Inc. (2009). Zyloprim (allopurinol) package insert. Retrieved from https:/www.prometheuslabs.com/Resources/PI/Zyloprim.pdf

Relling, M. V., McDonagh, E. M., Chang, T., Caudle, K. E., McLeod, H. L., Haidar, C. E.,...Luzzatto, L. (2014). Clinical Pharmacogenetics Implementation Consortium (CPIC) guidelines for rasburicase therapy in the context of G6PD deficiency genotype. Clinical Pharmacology and Therapeutics, 96(2), 169-174. https://doi.org/10.1038/clpt.2014.97

Rousselot, P., Cayuela, J. M., Hayette, S., Recher, C., Leguay, T., Salanoubat, C.,...Ottmann, O. G. (2010). Dasatinib (Sprycel ${ }^{*}$ ) and low intensity chemotherapy for first-line treatment in elderly patients with de novo Philadelphia positive ALL (EWALL-PH-01): Kinetic of response, resistance and prognostic significance [Abstract 172]. Blood (ASH Annual Meeting Abstracts), 116(21).

Salles, G., Morschhauser, F., Lamy, T., Milpied, N., Thieblemont, C., Tilly, H.,...Cartron, G. (2012). Phase 1 study results of the type II glycoengineered humanized antiCD20 monoclonal antibody obinutuzumab (GA101) in B-cell lymphoma patients. Blood, 119(22), 5126-5132. https://doi.org/10.1182/blood-2012-01-404368

Sanofi-aventis. (2011). Elitek (rasburicase) package insert. Retrieved from http://products.sanofi.us/elitek/elitek.html

Sehn, L. H., Assouline, S. E., Stewart, D. A., Mangel, J., Gascoyne, R. D., Fine, G.,...Crump, M. (2012). A phase 1 study of obinutuzumab induction followed by 2 years of maintenance in patients with relapsed CD20-positive B-cell malignancies. Blood, 119(22), 5118-5125. https://doi. org/10.1182/blood-2012-02-408773

Seymour, J. F., Davids, M. S., Pagel, J. M., Kahl, B. S., Wierda, W. G., Miller, T. P.,...Roberts, A. W. (2013). Updated results of a phase I first-in-human study of the BCL-2 inhibitor ABT-199 (GDC-0199) in patients with relapsed/ refractory $(\mathrm{R} / \mathrm{R})$ chronic lymphocytic leukemia (CLL) [Abstract 7018]. Journal of Clinical Oncology (ASCO Annual Meeting Abstracts), 31(15 suppl).

Seymour, J. F., Davids, M. S., Pagel, J. M., Kahl, B. S., Wierda, W. G., Puvvada, S.,...Roberts, A. W. (2014). ABT-199 (GDC-0199) in relapsed/refractory chronic lymphocytic leukemia and small lymphocytic lymphoma: High complete-response rate and durable disease control [Abstract 7015]. Journal of Clinical Oncology (ASCO Annual Meeting Abstracts), 32(15).

Siegel, D., Martin, T., Nooka, A., Harvey, R. D., Vij, R., Niesvizky, R.,...Lonial, S. (2013). Integrated safety profile of single- agent carfilzomib: Experience from 526 patients enrolled in 4 phase II clinical studies. Haematologica, 98(11), 17531761. https://doi.org/10.3324/haematol.2013.089334

Siegel, D. S., Martin, T., Wang, M., Vij, R., Jakubowiak, A. J., Lonial, S.,...Jagannath, S. (2012). A phase 2 study of singleagent carfilzomib (PX-171-003-A1) in patients with relapsed and refractory multiple myeloma. Blood, 120(14), 2817-2825. https://doi.org/10.1182/blood-2012-05-425934

Sonneveld, P., Asselbergs, E., Zweegman, S., Van Der Holt, B., Kersten, M. J., Vellenga, E.,...Lokhorst, H. (2012). Carfilzomib combined with thalidomide and dexamethasone is a highly effective induction and consolidation treatment in newly diagnosed patients with multiple myeloma who are transplant candidate [Abstract 333]. Blood (ASH Annual Meeting Abstracts), 120(21).

Spina, M., Nagy, Z., Ribera, J. M., Federico, M., Aurer, I., Jordan, K.,...Group, F. S. (2015). FLORENCE: A randomized, double-blind, phase III pivotal study of febuxostat versus allopurinol for the prevention of tumor lysis syndrome (TLS) in patients with hematologic malignancies at intermediate to high TLS risk. Annals of Oncology, 26(10), 2155-2161. https://doi.org/10.1093/annonc/mdv317

Stephens, D. M., Ruppert, A. S., Maddocks, K., Andritsos, L., Baiocchi, R., Jones, J.,...Flynn, J. M. (2013). Cyclophosphamide, alvocidib (flavopiridol), and rituximab, a novel feasible chemoimmunotherapy regimen for patients with high-risk chronic lymphocytic leukemia. Leukemia Research, 37(10), 1195-1199. https://doi.org/10.1016/j.leukres.2013.06.006

Takeda Pharmaceuticals U.S.A., Inc. (2013). Uloric (febuxostat) package insert. Retrieved from http://general.takedapharm. com/content/file.aspx?applicationcode $=66$ b0b942-e82b46ad-886a-f4aa59f5f33c\&filetypecode=ULORICPI

Teva Pharmaceutical Industries Ltd. (2016). Treanda (bendamustine hydrochloride) package insert. Retrieved from http://www.treandahcp.com/pdf/TREANDA_final_PI.pdf

Tosi, P., Barosi, G., Lazzaro, C., Liso, V., Marchetti, M., Morra, E.,...Tura, S. (2008). Consensus conference on the management of tumor lysis syndrome. Haematologica, 93(12), 1877-1885. https://doi.org/10.3324/haematol.13290

Trifilio, S. M., Pi, J., Zook, J., Golf, M., Coyle, K., Greenberg, D.,...Mehta, J. (2011). Effectiveness of a single 3-mg rasburicase dose for the management of hyperuricemia in patients with hematological malignancies. Bone Marrow Transplantation, 46(6), 800-805. https:/doi. org/10.1038/bmt.2010.212

Wendtner, C. M., Hillmen, P., Mahadevan, D., Buhler, A., Uharek, L., Coutre, S.,...Chanan-Khan, A. A. (2012). Final results of a multicenter phase 1 study of lenalidomide in patients with relapsed or refractory chronic lymphocytic leukemia. Leukemia and Lymphoma, 53(3), 417-423. https://doi.org/10.3109/10428194.2011.618232

Wilson, F. P., \& Berns, J. S. (2014). Tumor lysis syndrome: New challenges and recent advances. Advances in Chronic Kidney Disease, 21(1), 18-26. https://doi.org/10.1053/j. ackd.2013.07.001

Witzig, T. E., Wiernik, P. H., Moore, T., Reeder, C., Cole, C., Justice, G.,...Vose, J. M. (2009). Lenalidomide oral monotherapy produces durable responses in relapsed or refractory indolent non-Hodgkin's Lymphoma. Journal of Clinical Oncology, 27(32), 5404-5409. https://doi. org/10.1200/JCO.2008.21.1169 